\title{
THE EFFECT OF MENTAL HEALTH AND PSYCHOSOCIAL SUPPORT (MHPS) TRAINING ON THE PUBLIC AWARENESS OF NEW HABITUAL ADAPTATIONS (NHA): A PILOT RESEARCH
}

\author{
Susanti Niman ${ }^{*}$, Habsyah Saparidah Agustina ${ }^{2}$, Sri Wahyuni ${ }^{3}$, Niken Yuniar Sari ${ }^{4}$, Retty \\ Octi Syafrini5, Basmanelly6, Ira Erwina7, Komarudin', Sukma Ayu Candra Kirana9, Mad \\ Zaini $^{8}$, Budi Anna Keliat10, Rita Rahayu' ${ }^{11}$, Lahargo Kembaren12
}

1. Bachelor Nursing Program, STIKes Santo Borromeus, West Bandung, Indonesia

2. Department of Mental Health Nursing, Faculty of Nursing, Universitas Padjadjaran, Bandung, Indonesia

3. Faculty of Nursing, Universitas Riau, Riau, Indonesia

4. Faculty of Health Science, Universitas Mitra Indonesia

5. Jambi Provincial Mental Hospital, Jambi, Indonesia

6. Prof. HB. Saanin Mental Hospital, Padang, Indonesia

7. Faculty of Nursing, Universitas Andalas, Padang, Indonesia

8. Faculty of Health Science, Universitas Muhammadiyah Jember, Jember, Indonesia

9. STIKes Hang Tuah, Surabaya, Indonesia

10. Department of Mental Health, Faculty of Nursing, Universitas Indonesia, Depok

11. STIKes Sukabumi, Sukabumi, Indonesia

12. Mardzuki Mahdi Mental Hospital, Bogor, Indonesia

\section{Article Information}

Received: 18 August 2021

Revised: 12 October 2021

Accepted: 20 November 2021

\section{*Corresponding Author}

Susanti Niman

susanti@stikesborromeus.ac.id

\section{DOI}

10.20884/1.jks.2021.16.3.1869

\begin{abstract}
Mental health condition of many people has been impacted by the COVID-19 pandemic. The psychological distress felt by many has been brought by changes in their physiology, such as reduced immune system responses, increased risk of infection, and mental health problems. Therefore, mental health and psychosocial support (MHPS) training in the community is needed to actively maintain good mental and physical health. The objective of this research was to identify the effect of mental health and psychosocial training on the public awareness of the adaptation of new habits. A total of 44 participants took part in a mental health and psychosocial support training program. A pre-experimental design with a one-group pretestposttest approach was used. Result showed that there was a significant difference between the awareness of the adaptation of new habits before and after the training ( $p$-value $=0.001)$. It can be concluded that mental health and psychosocial support training for the community can independently increase the public awareness of the adaptation of new habits.
\end{abstract}

Keywords: COVID-19; mental health and psychosocial support; new adaptation habits; pandemic 


\section{INTRODUCTION}

The COVID-19 outbreak became increasingly widespread towards the end of January 2020 and drew worldwide attention. There were reports of two COVID-19 cases in Indonesia during early March 2020, which increased to 1285 cases by the end of the month and was spread across 30 provinces, including Jakarta, West Java, Banten, East Java, and Central Java (Ministry of Health of the Republic of Indonesia, 2020a). According to data from the Ministry of Health on May 10, 2021, the number of COVID-19 cases in Indonesia was 1,718,575, with 47,218 deaths (National Task Force for COVID-19, 2021). Although COVID-19 is considered disastrous due to the high number of positive and death cases, public awareness about the pandemic as a stressor remains limited.

According to Prentice et al. (2020), an individual's mental state can be affected by stressors. An example of a stressor would be the severity and uncertainty surrounding the pandemic. These factors can cause significant stress to any individual in society due to the lack of information about the COVID-19 virus, the use of personal protective equipment, social restrictions, as well as stigmatization and the spread of false information, which have significant psychosocial consequences in society. Moreover, the emotional ties between individuals to their families and communities may suffer due to self-quarantine measures implemented at home or in the hospital, thus contributing to weakened social support. Additionally, the stigma and discrimination caused by the spread of misinformation has worsened the stress response of COVID-19 patients (Hyun et al., 2020). Therefore, this complex situation requires all parties to quickly adopt new health protocols and acquire information about COVID-19 since individuals and communities may experience mental health issues due to the conditions caused by the COVID-19 pandemic (Sim \& How, 2020).

Previous research showed that the COVID-19 pandemic caused an increase in mental health issues. In Thailand, it was discovered that $52.1 \%$ of 3555 respondents experienced moderate to severe anxiety during the pandemic, while about $48.8 \%$ experienced moderate to severe anxiety at the onset of COVID-19 (Wong et al., 2020). Additionally, a mental health survey conducted by the Association of Indonesian Psychiatric Specialists with 1552 respondents, found that there was a correlation between the COVID-19 pandemic and mental health issues, such as anxiety and depression in $63 \%$ and $66 \%$ of the respondents, respectively (Indonesian Association of Psychiatrists, 2020). Similarly, other foreign and domestic research showed that the COVID-19 pandemic has caused stress, anxiety, and depression in individuals.

In addition to causing mental health issues, the COVID-19 pandemic has also triggered behavioral changes in individuals as a form of preventive measure against the virus. Subsequently, the presence of mental health issues and behavioral changes highlights the importance of mental health interventions. Thus, preventive services should be provided by mental health professionals for individuals who are at risk of developing mental health issues due to the COVID-19 pandemic (Shuja et al., 2020).

Mental health prevention is concurrent with the Sustainable Development Goals (SDGs). The third goal among the SDGs in point 3.4 aims to promote mental health and well-being (Pacific, 2016). Similarly, the World Health Organization (WHO) also implements a comprehensive mental health action program (Jordans \& Kohrt, 2020; Prentice et al., 2020).
Therefore, it is important for health workers to provide preventive and promotional measures against mental health issues to the community and encourage active participation.

Mental health and psychosocial support (MHPS) are one of the major preventive and promotional efforts that could improve the mental health of individuals. Maintaining a healthy mental state is crucial during a crisis since it can improve physical health, productivity, and the formation of a social network (Sim \& How, 2020). Therefore, MHPS is an effective response to emergencies, such as the COVID-19 pandemic.

The aim of MHPS is the improvement of psychological wellbeing, which includes preventing and treating mental and psychosocial disorders. This type of support integrates biological, psychological, and sociocultural approaches to health, social, education, and community development (Keliat \& Marliana, 2018). The Indonesian Mental Health Nurses Association has provided comprehensive mental health and psychosocial training to volunteers (the medical community, students, and the public) to actively maintain their mental and physical health.

One of the objectives of the mental health and psychosocial training conducted by the Mental Health Nurses Association is for trainees to engage in new habitual adaptation activities, which included five activities to boost physical immunity, six activities to boost mental immunity, seven activities to prevent physical transmission, four activities to prevent mental health problems, six activities to prevent family mental health problems, and one activity to prevent community mental health problems. Although the Ministry of Health and the Association of Indonesian Mental Health Nurses have compiled a guidebook of mental health and psychosocial support, it is not widely used by the public. Therefore, this research aims to determine the effect of mental health training on the awareness of adapting new habits among trainees.

\section{METHOD \\ Study design}

This study used a pre-experimental design with a one group pre- and posttest approach.

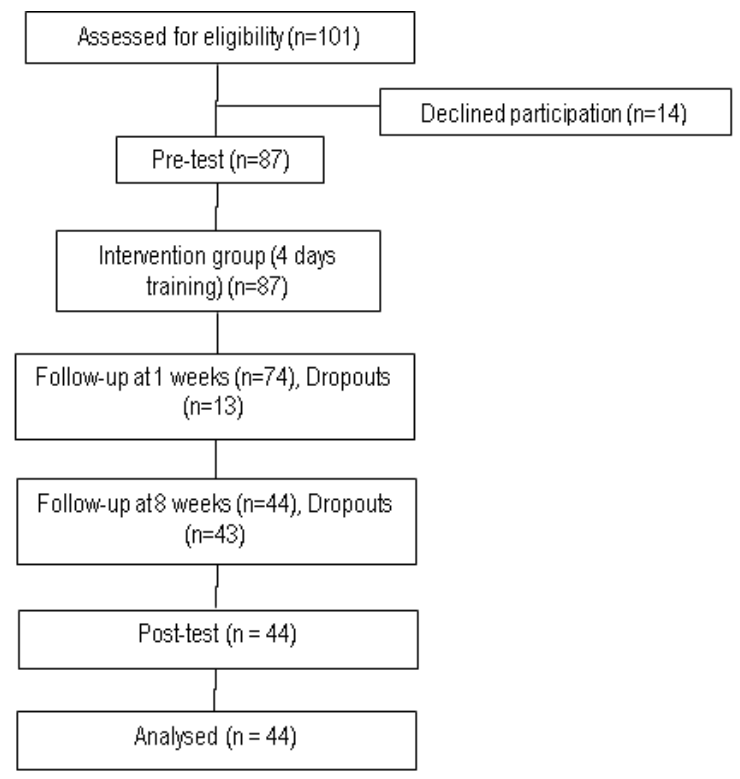

Figure 1. Flow chart of the participants in the study 


\section{Sample}

This research employed convenience sampling and included all nurses and nursing students who were willing to participate in a four-day online training. This was then followed by 8 weeks of filling out the new habitual adaptation (NHA) form. A total of 44 respondents fulfilled the research criteria.

\section{Instrument}

The material used in this research was the Mental Health and Psychosocial Support Guidebook, which consisted of 29 NHA activity instruments, including 5 items to measure activity to increase physical immunity (score 0-5), 6 items to increase mental immunity (score 0-6), 7 items to prevent physical transmission (score 0-7), 4 items to prevent problems with mental health (score 0-4), 6 items to prevent family mental health problems (score $0-6$ ), and 1 item to prevent community mental health problems (score 0-1). Each statement item has two options, if the respondents have completed the activity, they can reply with "yes" and receive a score of 1 . The second option is to reply with "no" if they did not complete an activity and receive a score of 0 . Furthermore, the scores were converted to a scale of 0-100. Meanwhile, the NHA instrument validity test results range from 0.236 to 0.611 , with a Cronbach alpha of 0.89 .

\section{Intervention}

Participants attended a 4 days on-line training. A total of 29 new habitual adaptation activities were taught during the training session, which included improving physical immunity (by nutritious eating, drinking, exercising, sunbathing, and sleeping), and increasing mental immunity (by relaxing physically, emotions, thoughts, behavior, relationships, and positive spirituality). Prevention of physical transmission included social and physical distancing by wearing face masks, hand washing, avoiding overcrowding, coughing/sneezing etiquette, and cleaning cell phones. Similarly, the prevention of mental health problems included deep breath, ensuring accurate information, acting on government recommendations, and evaluating actions taken. Lastly, the prevention of family mental health problems included family meetings, family awareness of health problems, decision-making capacity in the family, care in the family, and a conducive environment that supports the use of health facilities.

After the training, participants then were asked to implement the NHA activities for eight weeks and reported it through an online survey tool. The tool included descriptions of NHA activities that could boost physical and mental immunity and prevent physical transmission, as well as individual, family, and community mental health problems.

\section{Data Collection}

The link filled by the respondents was double checked each day. Meanwhile, the participants filled out the link each day to see if they are motivated to practice new habitual adaptation activities independently. During this research, online monitoring was done by the research team with the hope that the respondents would implement the activity in the future even if they are no longer monitored.

\section{Data Analysis}

The data was analyzed to determine the respondents' characteristics and perseverance towards the training program. Bivariate analysis was then performed using the paired t-test to determine the difference in the mean value of
29 new habitual adaptation activities performed independently during the first and eighth weeks.

\section{Ethical Consideration}

This research has passed the ethical test from the Ethics Committee of the Faculty of Nursing, University of Indonesia, with the number: SK-146/UN2.F12. D1.2.1/ETIK 2020. Additionally, online informed consent forms were obtained from the participants to indicate their willingness to participate in the activities performed.

\section{RESULTS}

As many as 87 individuals took part in the pretest on the first day of the training program, but only 74 respondents took part NHA implementation on the first week. A total of 44 respondents were analyzed as they have fully filled the Google Forms Charging Monitoring activity from the first to the eighth week.

\begin{tabular}{|c|c|c|}
\hline $\begin{array}{l}\text { Table 1. Participants' } \\
\text { implementation }\end{array}$ & characteristics & and \\
\hline Characteristics & $\begin{array}{l}\text { Week } 1 \\
\mathrm{~N}=74(\%)\end{array}$ & $\begin{array}{c}\text { Week } 8 \\
\mathrm{~N}=44(\%)\end{array}$ \\
\hline \multicolumn{3}{|l|}{ Age group } \\
\hline Late adolescence & $56(75.7)$ & $40(90.9)$ \\
\hline Young adult & $12(16.3)$ & $4(9.1)$ \\
\hline Middle age & $6(8.0)$ & 0 \\
\hline \multicolumn{3}{|l|}{ Gender } \\
\hline Male & $8(10.8)$ & $6(13.6)$ \\
\hline Female & 66 (89.2) & $38(86.4)$ \\
\hline \multicolumn{3}{|l|}{ Occupation } \\
\hline College student & $56(75.7)$ & $40(90.9)$ \\
\hline Health worker & 12 (16.3) & $4((9.1)$ \\
\hline Lecturer & $3(4.0)$ & 0 \\
\hline Health cadre & $3(4.0)$ & 0 \\
\hline
\end{tabular}

Table 1 demonstrates characteristics of the participants who took part in the NHA implementation after the 4 days training. They were mostly female, late adolescence. And college students. However, there was a decrease in the number of participants who implemented the NHA activities between the first and eighth weeks.

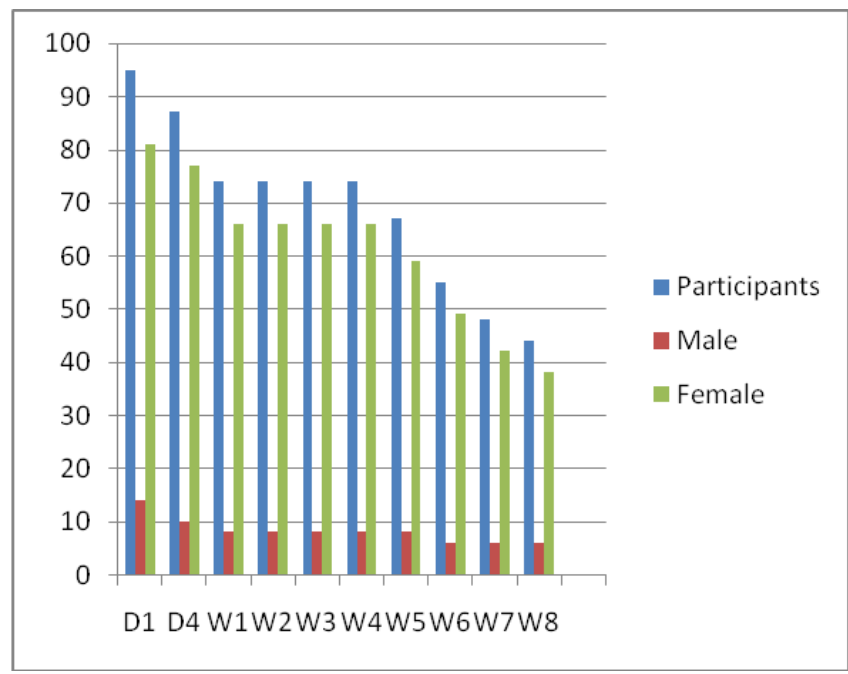

Figure 2. Training participants' sustainability

According to Fig. 2, the number of participants decreased by $8.4 \%$ on day 4 and by $22.1 \%$ on the first week after recruitment. The number of participants who implemented 
and reported their NHA through the form was relatively stable from week 1 to week 4 , but decreased by $29.5 \%$ in week 5 . Moreover, there was a decrease in weeks 6,7 , and 8 by
$42.1 \%, 49.5 \%$, and $46.3 \%$, respectively. At the end of the research period, there were only 44 participants who completed all activities.

Table 2. The average distribution of participants' new habitual adaptation activities before and after MHPS training $(\mathrm{n}=44)$

\begin{tabular}{lccc}
\hline & Before, mean (SD) & After, mean (SD) & p-value \\
\hline Increased physical immunity & $69.09(11.77)$ & $100(0.00)$ & 0.001 \\
Increased mental immunity & $72.30(10.75)$ & $100(0.00)$ & 0.001 \\
Prevention of physical transmission & $85.05(6.13)$ & $100(0.00)$ & 0.001 \\
Prevention of individual mental health problems & $85.05(6.13)$ & $100(0.00)$ & 0.001 \\
Prevention of family mental health problems & $61.70(18.17)$ & $100(0.00)$ & 0.001 \\
Prevention of public mental health problems & $31.82(47.11)$ & $100(0.00)$ & 0.001 \\
\hline
\end{tabular}

According to Table 2, the average score for the five physical immunity enhancement activities performed by participants before training was 69.09 , with a standard deviation of 11.77 . All activities to increase physical immunity were completed in the eighth week after training, with a mean and standard deviation of 100 and 0.0 respectively. The statistical tests resulted in a value of 0.001 , which implies that there is a significant improvement in the physical immunity of the participants before and after training. The six mental immunity enhancement activities completed by participants before the training led to an average and standard deviation score of 72.30 and 10.75 , respectively. After the training, all participants performed activities to boost mental immunity, and the statistical test resulted in 0.001 . According to Table 2 , activities related to the prevention of physical transmission, as well as individual and public mental health problem prevention, could all be done by the participants after the training, as indicated by an average activity score of 100 and the statistical result of 0.001 .

Table 3. Differences in awareness to practice adaptation activities to new habits before and after training ( $n=44)$

\begin{tabular}{lcccc}
\hline Variable & Mean & SD & SE & p-value \\
\hline $\begin{array}{l}\text { Awareness of new } \\
\text { habitual adaptation }\end{array}$ & & & & \\
$\begin{array}{l}\text { activities } \\
\quad \text { Before training }\end{array}$ & 61.68 & 11.60 & 1.75 & 0.001 \\
$\quad$ After training & 100.00 & 0.00 & 0.00 & \\
\hline
\end{tabular}

According to Table 3, the average level of awareness of new habitual adaptation in the first measurement was 61.68 with a standard deviation of 11.60. Meanwhile, in the second measurement, the level of awareness was 100.00 with a standard deviation of 0.00 . The mean difference between the first and second measurements is 38.32 with a standard deviation of 11.60 . The statistical tests resulted in a $p$ value of 0.001 , which implies that there is a significant difference in the public awareness of adapting new habits before and after the training.

\section{DISCUSSION}

The results showed that there were differences in the characteristics and new habitual adaptation activities before and after the training. According to the demographic data, most of the participants were nursing students engaged in online learning activities during the COVID-19 pandemic. This may be because students who study online from home or boarding houses have greater flexibility in scheduling training activities than nurses who work in hospitals, clinics, or health centers. Additionally, it was observed that lecturers at nursing institutions promoted their nursing students to participate in the training as part of their required learning.

Mental Health and Psychosocial Support is a brief immersion training program for mental health who work with populations that have endured severe adversities and trauma, such as pandemics and disasters. The training taught participants to apply collaborative and contextually sensitive approaches to enhance social connectedness and resilience in families and communities (Saul \& Simon ,2016). Mental health nurses who play a role in primary prevention perform nursing interventions to support mental health and psychosocial in the form of training.

The MHPS training was conducted through Zoom. This is a broad-spectrum community-based approach that aims to improve the mental health of the community through resilience and obedience to the preventive measures of COVID-19. Furthermore, it is an effective method since it was discovered that respondents came from various provinces, including the western, central, and eastern parts of Indonesia. Therefore, conducting the training through Zoom helped to overcome the logistical challenges of conducting physical classes.

By completing 29 adaptation exercises for new habits, it was discovered that there was a significant change in the respondents who completed the MHPS training towards their families, friends, and surrounding communities. During the first four days of training, respondents emphasized the importance of having a nuclear family and fostered families. Additionally, it was reported that the nuclear and foster families of the respondents could perform the NHA activities as the respondents. This is consistent with previous research that stated that mentally healthy individuals are more obedient and willing to comply with the required health protocols. This concerted effort within the community is critical for overcoming the pandemic (Bhagra et al., 2020). COVID-19 cannot be eradicated solely through diagnostic tests, treatment, or vaccination. Everyone can actively contribute to the prevention of COVID-19 through self-control and self-discipline. The health and safety of individuals can be maintained through the adoption of new habits in daily life. Additionally, the World Health Organization (WHO) recommends social and physical distancing to prevent the transmission of respiratory droplets, as well as hand washing, and the use of masks to prevent viral load spread (Jamaludin et al., 2020).

The Ministry of Health has published a guidebook for mental health and psychosocial support for healthy groups that can 
be done in the form of health promotion (Ministry of Health of the Republic of Indonesia, 2020b) This research aims to assess the readiness of respondents to engage in 29 new habitual adaptation activities by requesting each of them to self-report their activities on the link provided. This was explained during the four days of training activities through Zoom. The results of this research indicated that mental health and psychosocial support training leads to an increased awareness of adaptation to new habits. Previous research has shown that training may improve the performance, perseverance, and knowledge of individuals (Karaca \& Kose, 2020).Individual awareness can also be increased through training, while education delivered through a training program is more effective when it is focused on behavioral patterns (Contento, 2008; Ranganath et al., 2020). Therefore, conducting the training helped trainees to have new behavioral like NHA.

According to the results of the analysis, not all training participants had completed all 29 NHA activities even when they visited the NHA link provided on the first day of training. However, $80 \%$ of the participants completed more than $50 \%$ of the daily activities from the second day of training until the fourth week of training. Furthermore, the participants reported that they completed $100 \%$ of the activities once a week from week five to week eight. According to previous research, knowledge and practice transfer can cause participants to disseminate information to their home, which allows each household to control the spread of the disease (Radhika et al., 2019). The practice of adopting new habits of behavior carried out by training participants is felt to have an impact on health and in preventing the transmission of COVID-19 so that participants carry out behaviors independently and this has the potential to be followed by family members who live in the same house.

The average number of new habitual adaptation activities performed by participants increased between before and after the training. Firstly, the participants were engaged in only three activities before the training, which included eating nutritious foods, drinking water, and sleeping. After the training become five activities (exercising, sunbathing). Six activities were included to enhance mental immunity before training, but the participants completed only two of them, which were physical relaxation and positive spirituality. Meanwhile, all participants reported that they completed all activities taught after the training. Before the training, the participants were engaged in only five physical transmission activities, which included maintaining social and physical distance, wearing masks, washing hands, and avoiding crowds. All participants (100\%) reported that they completed all above-mentioned activities and two activities (coughing/sneezing etiquette, and cleaning cellphones activities) after the training. Whereas for individual mental health prevention activities, before the training, the participants were engaged in only one activity, which was adhering to government recommendations. After the training, all participants $(100 \%)$ reported that they engaged in all activities taught. The prevention of family and community mental health problem component had six and one activities, respectively, as well as an average score of $61.70 \%$ and $31.82 \%$, respectively. Both scores increased to $100 \%$ after the training. All participants $(100 \%)$ could implement new habitual adaptation activities on their own after receiving training and assistance during the independent practice.

In terms of limitations, the data obtained in this study are only daily reports that were self-submitted by respondents through the Google Forms link and communication through social media. Direct observations or reports through photos/videos by the research team were not conducted, thus, the risk of bias still exists. In addition, the absence of a control group means that this research could not measure the effectiveness of the intervention.

\section{CONCLUSION AND RECOMMENDATION}

This research concluded that online mental health and psychosocial support training that integrates theory and independent practice could increase the awareness of how 29 adaptive measures could be formed into new habits. Additionally, a practical recommendation based on the results of this study is that MHPS training can be conducted at all levels of society to enable the community to implement 29 new habitual adaptive measures as part of their active role of containing the COVID-19 spread. Further research could compare the control group to the intervention group and observe the intervention activities directly or through videos.

\section{ACKNOWLEDGMENT}

The researchers would like to thank the respondents who were willing to take the time to participate in this study for eight weeks and the Association of Indonesian Mental Health Nurses who have supported this research.

\section{REFERENCES}

Bhagra, O., Patel, S. R., \& Chon, T. Y. (2020). An integrated and intergenerational community response to promote holistic wellbeing during the COVID-19 pandemic. EXPLORE, 16(5), 283-285. https://doi.org/10.1016/j. explore.2020.05.018

Contento I. R. (2008). Nutrition education: linking research, theory, and practice. Asia Pacific Journal of Clinical Nutrition, 17(Suppl 1), 176-179. https://pubmed.ncbi. nlm.nih.gov/18296331

Hyun, J., You, S., Sohn, S., Kim, S.-J., Bae, J., Baik, M., ..., Chung, U. S. (2020). Psychosocial support during the COVID-19 outbreak in Korea: Activities of multidisciplinary mental health professionals. Journal of Korean Medical Science, 35(22), e211. https://doi. org/10.3346/jkms.2020.35.e211

Indonesian Association of Psychiatrists. (2020). Infografik Swaperiksa Cemas Depresi [Anxiety Depression SelfCheck Infographic]. Retrieved from http://pdskji. org/home

Jamaludin, S., Azmir, N. A., Ayob, A. F. H., \& Zainal, N. (2020). COVID-19 exit strategy: Transitioning towards a new normal. Annals of Medicine and Surgery, 59, 165-170. https://doi.org/10.1016/j.amsu.2020.09.046

Jordans, M. J. D., \& Kohrt, B. A. (2020). Scaling up mental health care and psychosocial support in low-resource settings: A roadmap to impact. Epidemiology and Psychiatric Sciences, 29, e189. https://doi.org/10.10 17/S2045796020001018

Karaca, A., \& Kose, S. (2020). The effect of knowledge levels of individuals receiving basic first aid training in Turkey on the applications of first aid. Nigerian Journal of Clinical Practice, 23(10), 1449-1455. https://doi.org/ 10.4103/njcp.njcp_686_19

Keliat, B. A., \& Marliana, T. (2018). Dukungan Kesehatan Jiwa Dan Psikososial [Mental Health and 
Psychosocial Support]. Faculty of Nursing Universitas Indonesia

Ministry of Health of the Republic of Indonesia. (2020a). Pedoman Pencegahan dan Pengendalian Corona Virus Diseases (COVID-19) [Guidelines for the Prevention and Control of Corona Virus Diseases (COVID-19)]. Retrieved from https://covid19.kemkes. go.id/protokol-covid-19

Ministry of Health of the Republic of Indonesia. (2020b). Pedoman Dukungan Kesehatan Jiwa dan Psikososial Pada Pandemi COVID-19 [Guidelines for Mental Health and Psychosocial Support in the COVID-19 Pandemic]. Retrieved from https://infeksiemerging. kemkes.go.id

National Task Force for COVID-19. (2021). Situasi COVID19 [COVID-19 Situation]. Retrieved from https://www.covid19.go.id

Prentice, C., Zeidan, S., \& Wang, X. (2020). Personality, trait El and coping with COVID 19 measures. International Journal of Disaster Risk Reduction, 51, 101789. https://doi.org/10.1016/j.ijdrr.2020.101789

Radhika, N. M. L., Gunathilaka, N., Udayanga, L., Kasturiratne, A., \& Abeyewickreme, W. (2019). Level of awareness of dengue disease among school children in Gampaha District, Sri Lanka, and effect of school-based health education programmes on improving knowledge and practices. BioMed Research International, 2019, 1-8. https://doi.org/10. $1155 / 2019 / 3092073$

Ranganath, R., Muthusami, J., Simon, M., Mandal, T., \& Kukkamulla, M. A. (2020). Female medical and nursing students' knowledge, attitudes, and skills regarding breast self-examination in Oman: a comparison between pre- and post-training. Journal of Educational Evaluation for Health Professions, 17, 37. https://doi.org/10.3352/jeehp.2020.17.37

Saul, J., \& Simon, W. (2016). Building resilience in families, communities, and organizations: A training program in global mental health and psychosocial support. Family Process, 55(4), 689-699. https://doi.org/10.1111/ famp. 12248

Shuja, H. K., Aqeel, M., Jaffar, A., \& Ahmed, A. (2020). COVID-19 pandemic and impending global mental health implications. Psychiatria Danubina, 32(1), 3235. https://doi.org/10.24869/psyd.2020.32

Sim, H., \& How, C. (2020). Mental health and psychosocial support during healthcare emergencies - COVID-19 pandemic. Singapore Medical Journal, 61(7), 357362. https://doi.org/10.11622/smedj.2020103

Wong, L. P., Hung, C.-C., Alias, H., \& Lee, T. S.-H. (2020). Anxiety symptoms and preventive measures during the COVID-19 outbreak in Taiwan. BMC Psychiatry, 20(1), 376. https://doi.org/10.1186/s12888-02002786-8

World Health Organization. (2016). Sustainable development goals (SDGs): Goal 3. Target 3.4 : By 2030, By 2030, reduce by one third premature mortality from noncommunicable diseases through prevention and treatment and promote mental health and well-being [poster]. Retrieved from https://iris.wpro.who.int/ handle/10665.1/12876 